\title{
"ENTRAMOS NUM ACORDO, MEU LEITE DIMINUIU E ELE PAROU DE MAMAR AOS POUCOS": O DESMAME EM TRÊS GERAÇÕES ${ }^{1}$ \\ "WE MADE A DEAL, MY MILK DIMINISHED AND HE STOPPED BREASTFEEDING LITTLE BY LITTLE": STOPPING BREASTFEEDING THROUGHOUT THREE GENERATIONS
}

\author{
Joseila Sonego ${ }^{2}$ \\ Isabel Cristina Pacheco Van der Sand ${ }^{3}$
}

SONEGO, J.; VAND DER SAND, I. C. P. Entramos num acordo, meu leite diminuiu e ele parou de mamar aos poucos: o desmame em três gerações. Revista Eletrônica de Enfermagem (on-line), v. 4, n. 1, p. 26 - 32, 2002. Disponível em http://www.fen.ufg.br.

RESUMO: Este trabalho trata de um estudo de caso, com abordagem qualitativa, que teve como objetivos conhecer as práticas relativas ao desmame utilizadas por mulheres-mães que possuem, entre si, laços familiares e identificar a influência do repasse de informações entre gerações no processo de desmame. Os dados foram coletados através de histórias de vida, contadas por sete colaboradoras, por meio de entrevista aberta. Utilizou-se a análise temática de MINAYO (1993) para análise dos dados. O estudo evidencia que o modo como as mulheres conduzem a alimentação de seus filhos tem relacionamento com a aprendizagem intergeracional, as condições sócio-econômicas, o contexto histórico e vivência de cada mulher.

UNITERMOS: enfermagem, práticas de desmame, aleitamento materno.

ABSTRACT: This is a study of case, with qualitative approach, which objectives are to know the practice of stopping breastfeeding by mothers that have familial relationship, and to identify the influence of transmission of information among generations in that practice. The data was gathered through life history, told by seven subjects, through open interviews. For the analysis of data was used the thematic analysis of MINAYO (1993). The study evidenced that style that the woman feeds her children has relation with the learning among generations, the social and economic conditions, the historic context and the experience of each woman.

KEY WORDS: nursing, practice of wean, breastfeeding

\section{INTRODUÇÃO}

No contexto da gravidez, percebemos que um dos assuntos importantes a serem discutidos é o aleitamento materno, que traz vantagens à mãe, à criança e à família. É um tema que está presente no nosso dia-a-dia de acadêmicos e profissionais da Enfermagem. Pensamos que ao estimularmos as gestantes para que amamentem seus filhos é preciso ter cautela para não impormos às mulheres a idéia de que somente através da amamentação garantem o sustento/saúde do bebê e mostram que ele é amado.

Ao falar em aleitamento materno, raramente lembramos que um dia esses bebês irão crescer, e suas mães precisarão desmamá-los. Acreditamos que o desmame ocorre de diferentes maneiras, dependendo de cada mulher, do meio onde ela vive, enfim do seu grupo cultural e social. Essa situação é que nos estimula e impulsiona a desenvolver um estudo com mulheres-mães, buscando responder a seguinte inquietação:

Quais são as práticas relativas ao desmame utilizadas por mulheres-mães que possuem, entre si, laços familiares?"

Com o propósito de responder a esta indagação os objetivos delineados foram:

- Conhecer as práticas relativas ao desmame utilizadas por mulheres-mães que possuem, entre si, laços familiares;

- Identificar a influência do repasse de informações entre gerações no processo de desmame;

\section{ALEITAMENTO MATERNO E DESMAME: NOTAS DA LITERATURA}

Amamentar ou não um filho constitui-se em uma tarefa que ultrapassa as barreiras do querer. A

\footnotetext{
${ }^{1}$ Artigo elaborado a partir do Trabalho de Conclusão de Curso, requisito parcial para obtenção do título de bacharel em enfermagem pelo curso de Enfermagem da Universidade Regional do Noroeste do Estado do Rio Grande do Sul (UNIJUí).

${ }_{2}^{2}$ Enfermeira, graduada pelo curso de Enfermagem, da Universidade Regional do Noroeste do Estado do Rio Grande do Sul - UNIJUÍ - RS.

Endereço: Av. Brasil, 23, Bairro São Geraldo, ljui/RS. CEP: 98-700-00. joseilasonego@bol.com.br

${ }_{3}^{3}$ Mestre em Enfermagem, docente do curso de Enfermagem da UNIJUí.Isabel@unijui.tche.br
} 
decisão materna de amamentar é um fato que poderá influenciar diretamente na concretização desse ato, porém a amamentação é um advento também social, que muda conforme a época em que vivemos. "[...] quando a mãe escolhe a maneira em que vai alimentar seu bebê, expressa, nessa decisão, influências da sociedade, do seu estilo de vida, da sua história pessoal e de sua personalidade" (MALDONADO, 1981, p.53).

CABRAL \& TYRREL (1995) afirmam que o estilo adotado pela mãe para atender as necessidades de seus filhos, aqui destacando a alimentação, é resultado de um processo de acumulação de informações/conhecimentos que são transmitidos de geração a geração por meio da herança cultural específica de cada grupo. Desta forma, as questões culturais também terão influência nas atitudes adotadas pelas mulheres para conduzirem a alimentação de seus filhos.

No processo de alimentação da criança tem destaque o aleitamento materno. Assim, pensamos ser importante considerar na assistência prestada ao binômio mãe e filho a idéia de que a separação que ocorre entre eles durante o nascimento configura-se como um choque físico e emocional para ambos e a amamentação, quando concretizada, permitirá que a separação aconteça lentamente e seja reelaborada gradualmente (PRYOR, 1981).

O que une a dupla de amamentação é o afeto mútuo, sendo essa uma relação intensa em que mãe e filho precisam um do outro, tanto físico quanto emocionalmente e essa união, depois de estabelecida, torna-se difícil de desfazê-la, "[...] a criança tem necessidade de contato com a mãe, de amor e de tranqüilidade, obtidos através de todos os seus sentidos enquanto mama" (PRYOR, 1981, p.16).

As atitudes maternas em relação à alimentação da criança refletirão em diferentes sentimentos e expectativas da mulher em relação a si própria, enquanto mãe, e ao filho. Assim, se a situação de aleitamento materno for concretizada, poderão surgir fantasias, medos e emoções em relação à qualidade de seu leite e de sua competência em cuidar de um recém-nascido (MALDONADO, 1981).

Como podemos perceber, a questão do aleitamento materno envolve de forma relevante os aspectos emocionais da mulher, como também é um processo de aprendizagem e adaptação entre mãe e filho. Gradativamente, o binômio irá descobrindo-se e construindo um modo particular de comunicação, em que um entenderá o outro através de gestos e olhares. Ser mãe é um processo a ser desenvolvido e depende dos sentimentos que a mulher possui sobre esse novo papel social.

Em relação ao processo de desmame, MARCON (1996, p.44) refere que este:

"encontra-se relacionado à experiência vivida pelas mulheres durante 0 período de amamentação. É durante este tempo que as mulheres conseguem perceber a existência de diferentes, sucessivas e significativas mudanças e alterações tanto em relação aos seus sentimentos, quanto nas mais diferentes áreas de sua vida demonstrando também que, de certo modo, a forma como vivenciam esta experiência, é fortemente influenciada pela forma como experimentam e percebem vivências anteriores à experiência da amamentação, ou seja, o período da gravidez, ou pela história pessoal e familiar de amamentação pregressa e por seus conhecimentos anteriores."

Mãe e filho é que precisariam decidir sobre o tempo que deve durar a amamentação, sendo que, o momento de interrompê-la definitivamente "é quando algum dos parceiros está definitivamente pronto para abandoná-la" (PRYOR, 1981, p.231). A autora afirma ainda que o desmame é parte do processo de crescimento da criança e do amadurecimento da mãe.

A amamentação tem um papel vital na separação da mãe e filho. "O mamar do bebezinho pode ser visto como um segundo cordão umbilical que deve, se possível, ser cortado progressivamente, sem traumas ou sentimentos de culpa para ambos. $O$ essencial é a postura com que se faz este corte e não o tempo que se leva" (OLIVEIRA, 1997, p.897).

RAPAPPORT et al. (1981, p.40) realizam algumas considerações sobre 0 significado psicológico do processo de desmame:
"[...] o momento de interrupção da amamentação concretizará diferentes posturas no relacionamento (da criança) com o mundo. Posturas estas que, embora iniciadas nestes momentos, tenderão a se expandir para todo o desenvolvimento futuro, ou seja, todas as modalidades de relações futuras poderão estar permeadas por este processo".

PRYOR (1981) relata práticas utilizadas por mulheres no processo de desmame para desencorajar o filho a desejar mamadas futuras. $\mathrm{Na}$ zona rural do México, por exemplo, as mães põem na mama pimenta do "chili", uma substância amarga que quando experimentada pela criança a mesma rejeita a mama. Já em certas regiões do Pacífico, as mamas são pintadas com tintas inofensivas, então os filhos estranham a aparência modificada e negam o seio. Outra técnica que é usada na Europa diz respeito ao fato das mães afastarem-se dos bebês por quatro ou cinco dias, deixando-os com o pai ou parentes. A idéia é que a criança, com a mãe ausente acostume a ficar sem a amamentação.

Os profissionais da enfermagem poderiam contribuir, nos momentos oportunos, para que o processo de desmame ocorresse de forma natural e sem deixar traumas para a criança e para a mãe. Os enfermeiros precisariam estar juntos com as famílias, prestando apoio para fortalecê-las no enfrentamento das atividades diárias relacionadas à saúde (MARCON \& ELSEN, 2000). Nesse contexto, podemos incluir a alimentação da criança, que contempla, também, a amamentação e o desmame. Nesse período, o apoio de profissionais da saúde à mulher-mãe são importantes para que ela sinta-se segura e sabendo que não está sozinha, podendo pedir ajuda quando achar necessário. 
No que diz respeito ao desmame, é válido conhecermos as práticas utilizadas por mulheresmães para concretizá-lo e a maneira que essa vivência é experimentada por essas mulheres. Assim, os profissionais enfermeiros poderão pensar nessas situações e a partir delas terão a oportunidade de orientar outras mulheres que estão passando pela experiência do desmame.

\section{O PERCURSO METODOLÓGICO}

Considerando a forma interpretativa com que o objeto deste estudo foi tratado e a preocupação de investigar as práticas presentes no processo de desmame sob a perspectiva das colaboradoras do estudo, podemos classificá-lo como uma investigação qualitativa, sendo esta composta por um conjunto próprio de termos, conceitos e pressupostos. Esta abordagem é aqui entendida como aquela que:

"se preocupa com um nível de realidade que não pode ser quantificado. Ou seja, ela trabalha com o universo de significados, motivos, aspirações, crenças, valores e atitudes, o que corresponde a um espaço mais profundo das relações, dos processos e dos fenômenos que não podem ser reduzidos à operacionalização de variáveis" (MINAYO, 1996, p.21-22).

O estudo foi delineado com características de um estudo de caso, o qual é definido como pesquisa sobre determinado indivíduo, família, grupo ou comunidade para pesquisar aspectos variados de sua vida, é um estudo detalhado, em que se pretende apreender o máximo de informações sobre um contexto ou um acontecimento específico (BOGDAN \& BIKLEN, 1994).

O grupo de colaboradoras compreendeu sete mulheres-mães que passaram pelo processo de amamentação e desmame de seus filhos, independente do tempo que mantiveram 0 aleitamento materno. As mulheres-mães possuem, entre si, laços familiares e compreendem três gerações de uma mesma família. Sendo que, três delas são da segunda geração, duas da terceira e duas da quarta geração.

Para a coleta dos dados utilizamos a história de vida "tópica", de acordo com a abordagem de MINAYO (1993). As mulheres-mães, colaboradoras o estudo, foram convidadas a contar como aconteceu o processo de alimentação e desmame de seus filhos através de uma conversa entre pesquisador colaborador, a qual foi gravada e posteriormente transcrita na íntegra para análise final.

A técnica para a coleta das histórias de vida relacionadas ao período em que as mulheres destinavam cuidados aos seus filhos em relação a alimentação e o desmame, foi a entrevista aberta, duas questões norteadoras:

1) Conte como aconteceu a alimentação dos seus filhos quando eles eram pequenos.
2) Agora fale como aconteceu o desmame de seus filhos e como foi para você desmamá-los.

Neste estudo, as entrevistas foram analisadas à luz das orientações metodológicas de MINAYO (1993), que preconiza os seguintes passos: primeiro, a ordenação dos dados coletados (transcrição de fitas-cassetes, releitura do material, organização dos relatos, organização dos dados de observação); segundo, a classificação dos dados (leitura exaustiva e repetida dos textos, constituição de um corpus ou de vários corpus de comunicação se o conjunto das informações não é homogêneo, leitura transversal de cada corpo com o recorte de unidade de registro,e enxugamento da classificação por temas mais relevantes); e, terceiro a análise final (levando em conta os objetivos da pesquisa e os temas que emergem das entrevistas).

As entrevistas foram gravadas em fita cassete com a aquiescência das colaboradoras, que foram informadas dos objetivos da pesquisa e assinaram "Termo de Consentimento Informado", que lhes garantiu anonimato e o uso das informações apenas para fins científico, conforme a Resolução 196/96 (BRASIL, 1997). Cabe destacar que o projeto do estudo não foi avaliado por Comitê de Ética, em virtude de que este, na Universidade Regional do Noroeste do Estado do Rio Grande do Sul, instituição na qual as pesquisadoras estão alocadas, encontrase em fase em fase de implantação.

\section{OS RESULTADOS DO ESTUDO: análise e discussão}

As práticas relatadas pelas colaboradoras tiveram o objetivo de concretizar o desmame total da criança (retirada total do leite materno), pois a implementação de aleitamento materno exclusivo não fez parte do cotidiano das mulheres-mães deste estudo.

O estudo evidencia que há uma certa preferência das mulheres-mães entrevistadas em realizar o desmame de seus filhos de forma progressiva e que não traga sofrimento às crianças. Elas referiram que essa opção não aconteceu por acaso, ela tem uma história, e sua protagonista principal é DAFNE, uma das colaboradoras deste estudo.

DAFNE, sobrinha das colaboradoras que compreendem a segunda geração da família estuda, foi amamentada ao peito por sua mãe até o momento em que esta soube de uma nova gestação. Frente esse acontecimento, sua mãe optou por desmamá-la rapidamente, distanciando-se da filha e entregando-a aos cuidados do esposo e de suas irmãs.

Tal medida desencadeou sofrimento à mãe, à criança e às pessoas que vivenciaram o processo de desmame, entre essas estavam HEBE, ATENA e HÉSTIA, tias de DAFNE. Essas senhoras e a própria DAFNE nos contam um pouco dessa história e a sua repercussão na vida de cada uma delas:

"E eu sempre desmamei aos poucos, me lembro quando nós era solteira que foi desmamado a DAFNE, que é filha da $G$. 
minha irmã mais velha, ela tirou de soco quando ela notou que tava grávida. E a DAFNE aquela vez mamava de dia e de noite, então ela chorava de dia e de noite, daí uma das tias e o pai dela caminhava, passeava com ela pra cá e pra lá e ela gritava quase dia e noite até que ela se acostumou; porque era só peito e ela tirou de soco" (HEBE, segunda geração)

"Sabe, eu me lembrei agora de quando a $G$. desmamou a DAFNE, a G. chorava de ver a $D A F N E$ chorando, coitada, ela teve que desmamar porque ficou grávida, e a DAFNE chorava de fome, ela desmamou de soco, foi por isso" (ATENA, segunda geração)

"Quando eu tava desmamando minhas filhas eu me lembrava da época que nós cuidava a DAFNE que a G. queria desmamar ela; mas ela quis desmamar de soco, daí a DAFNE levou um tempo pra se acostumar sem o leite da mãe, eu me lembro que ela chorava, sofria e eu não queria que acontecesse isso, então eu desmamava devagarinho, ia diminuindo aos poucos a amamentação" (HÉSTIA, segunda geração)

“... nós tava em casa e a mãe falava que... ela criou nove filhos e a mais velha que era eu diz que eu chorei muito quando fui desmamada, então ela contava essa história aí, assim, sofria ela e sofria o nenê também, que era eu. Ela resolveu me desmamar de repente, diz que levou lá pras tias me cuidarem, aí eu chorava muito, e isso foi uma experiência pra ela negativa, aí um dia ela contou que os outros que os outros ela desmamou assim devagarinho, gradativo, então assim, essas coisas a gente ouvia falar e tendo em vista isso a gente aprendeu..." (DAFNE, terceira geração)

Como pode ser visualizado nas falas, as mulheres-mães têm preferência por realizar um desmame progressivo, sendo que as da segunda geração optam por interromper o aleitamento materno primeiramente de dia e após no turno da noite. Constatamos que para o filho não sentir falta $e$ solicitar o peito durante o dia, elas utilizam-se de brincadeiras para concentrar a atenção da criança, e em conseqüência, conseguir passar um período maior sem amamentar. Referem que esta prática proporciona um desmame rápido e tranqüilo. Observemos as falas a seguir:

"Daí depois quando eu desmamei, aos poucos, fui tirando aos poucos, não dava... fui cuidando... primeiro não dava de dia, entertia eles né, e de noite depois... num instante eu desmamava" (HEBE, segunda geração)

"Quando desmamei ela fui diminuindo de dia [...] Daí de noite se ela se acordava eu dava de mama, em três dias eu desmamei ela, mas quando ela se lembrava, ela procurava, daí eu desviava, disfarçava com outros brinquedos, dava chazinho..." (HÉSTIA, segunda geração)

“... a mãe, depois de mim, ela desmamava de dia e depois de noite, eu aprendi com ela, foi ensinamentos passados por minha mãe [...] então quando chegou a hora de desmama os meus eu fui desmamando assim devagarinho. Eu não senti, a criança não sentiu também [...] foi tranqüilo, fui diminuindo as do peito e aumentando a mamadeira, e de noite do mesmo jeito" (DAFNE, terceira geração)

"...daí foi, foi... que ele acabou largando (o peito), eu não tive que fazer alguma coisa pra desmamar, não foi difícil porque eu ia diminuindo, então o nenê foi acostumando, foi uma conseqüência[...] Nós entramos num acordo, foi acontecendo junto, meu leite diminuiu e ele parou de mamar aos poucos, assim, foi bom pra mim e foi bom pra ele" (AFRODITE, quarta geração)

A opção pelas práticas de desmame pode ser determinada pelos ensinamentos compartilhados na rede social e transmitidos entre as gerações de uma família, como é contado por DAFNE. Assim, percebemos que os costumes, as crenças e as práticas específicas de um grupo familiar terão influência na maneira com que as mulheres irão conduzir a criação de seus filhos, incluindo o processo de amamentação e desmame.

Tal situação possibilita explicitarmos a definição de cultura entendida como um conjunto de comportamentos e saberes de determinado grupo que são adquiridos e compartilhados pelos seus membros (CABRAL \& TYRREL, 1995). Significa que questões culturais, como também a subjetividade de cada mulher, poderá influenciar na forma com que irá se proceder os cuidados em relação a alimentação das crianças.

DAFNE conta que o fato dela trabalhar fora de casa fez com que introduzisse alimentação por meio de mamadeira na rotina de seus filhos, pois precisava "acostumá-los" para o dia que não estaria todo tempo com eles. Refere que tal prática impediria que as crianças sofressem pela falta do aleitamento materno, tal como aconteceu consigo mesma.

"Bom, o desmame foi assim, como eu trabalhava, tive três meses de licença, então aí, por isso que eu já comecei dar mamadeira também antes, não só como complemento, mas para acostumar a criança que depois eu ia trabalhar, e isso aí fazia com que a criança não sofresse né, entendeu? Não passasse fome" (DAFNE, terceira geração).

MARCON \& ELSEN (2000, p.155) apontam que "a urbanização associada a uma série de outras mudanças como, por exemplo, a inserção da mulher no mercado de trabalho, a redução no número de filhos constituem algumas das alterações que influenciaram sobremaneira a forma de criar os filhos". A afirmação das autoras pode ser percebida 
no cotidiano de DAFNE, que mudou a alimentação dos seus filhos em virtude de estar inserida no mercado de trabalho.

As mudanças que parecem ocorrer na maneira com que as mulheres cuidam de seus filhos, aqui enfatizando a alimentação, encontram-se em estreito relacionamento com as necessidades de sobrevivência, os valores culturais e os avanços da ciência, fatores que juntos permitem essa movimentação (CABRAL \& TYRREL, 1995).

Como mencionado anteriormente por DAFNE, ela teve por direito 90 dias de licença maternidade, o que a possibilitou "preparar" seus filhos para o desmame total. É válido lembrar que a situação vivenciada por ela difere do cotidiano da maioria das mulheres de classes populares. Essas, por sua vez, em geral não se encontram inseridas no mercado formal de trabalho, e conseqüentemente, precisam abandonar o aleitamento materno antes do terceiro mês de vida da criança por imposição econômica/financeira. Por falta de amparo legal há a necessidade de optarem entre o aleitamento materno e o seu emprego, que muitas vezes, é a única fonte de renda da família.

As mulheres-mães que compreendem a segunda geração da família, por sua vez, trabalhavam no lar, realizando os afazeres domésticos e cuidando dos filhos, assim permanecendo todo tempo ao lado das crianças pequenas. Tal situação parece que dificultava a concretização do desmame, pois referem que ao ver a mãe, as crianças lembravam da amamentação e a solicitavam.

Frente a isso, no período de desmame, tentavam distanciar-se dos filhos pequenos, e esses passavam a receber atenção maior dos irmãos mais velhos e/ou das vizinhas/amigas que ofereciam ajuda. Quem nos conta a respeito dessa prática são as irmãs HEBE, ATENA e HÉSTIA:

"... eu me lembrava da DAFNE que chorou muito, daí eu cuidava pra começar a tirar aos poucos [...] daí eu cuidava pra pegar o quanto menos no colo quando que tinha fome, dava pros outros, assim, porque se tu pegava no colo tinha que dar mama." (HEBE, segunda geração)

“... tinha a $A$. que morava comigo e ela começou a pegar eles no colo, pra não ficarem no meu colo, se não eles queriam mama [...] a N. foi uma vizinha que ajudou a desmamar, que cuidava dela, ela parava perto, então levou a N. na casa deles, posar lá, posou lá umas três noites, três dias ela ficou com a $N$. lá, e depois ela me trouxe, desmamei assim." (ATENA, segunda geração)

“... o desmame foi fácil, porque ela era calma, não foi difícil, as vezes ela continuava procurando o seio de dia mas eu evitava, não tinha muito contato com ela durante o dia enquanto eu ainda dava de noite. Senão ela se aproximava, lembrava e queria, daí eu procurava sempre alguém pra dá atenção pra ela e eu ficava mais distante." (HÉSTIA, segunda geração)
ATENA, ao contar sobre a prática de desmame em que se distanciavam os filhos de suas mães, referiu que sua mãe também fazia uso dela e traz uma lembrança do passado:

"E sabe, pra minha mãe desmamar os filhos dela foi mais fácil, ela tinha nós e nós cuidava dos nenês pra ela, eu me lembro quando fui desmamada[...] me lembro que o A.(seu irmão) me colocava nas costas e me levava caminhar na roça quando eu queria mama, eles me entertiam e a mãe não me dava mais nada, botava um vestido bem afogado pra mim não botar a mão dentro, e quando nós tinha nossos filhos, ela ensinava pra fazer assim." (ATENA, segunda geração)

A fala de ATENA permite recorrermos a considerações em relação aos fatores que influenciam o comportamento humano. "O comportamento humano (...) é influenciado pela cultura, ou seja, pelas crenças, sentimentos, costumes, valores, compartilhados pelos membros de um grupo social e que são transmitidos de uma geração à seguinte através da aprendizagem" (ALENCAR,1982, p.20).

A estratégia de afastar as crianças de suas mães para que elas desistam do aleitamento materno também é empregada pelas mulheres de outras comunidades (VAN DER SAND, 1999; MARCON, 1996; MELATTI \& MELATTI, 1982; PRYOR, 1981).

Nosso estudo evidencia também que para a ocorrência do desmame de forma tranqüila e sem sofrimento, as mulheres-mães solicitavam ajuda de santos e pessoas da família, que haviam falecido, através de rezas e novenas. Acreditavam que a fé em seres superiores era um dos caminhos que auxiliaria para facilitar a interrupção do aleitamento materno. Observem as falas de HEBE e HÉSTIA:

“... quando era pra desmama, eu ia na missa, rezava pra Deus me ajudar, pedia pra Nossa Senhora, depois quando tinha o finado pai falecido eu rezava pra ela me ajudar, pro meu nenê dormir, pra não chorar, pra desmamar, pra ser fácil, eu sempre pedia pra Deus, aí me pegava com algum santo[...] o santo Antônio me ajudou muito e a santa Rita, eu rezei uma vez. E o F., então eu rezei pra minha mãe, que quando ela tinha morrido ele ainda mamava, e isso ajuda..." (HEBE, segunda geração)

“... eu tinha muita fé no santo Onofre que me ajudava, e pedia muito pra Medianeira de todas as Graças, fazia os Minutos de Concentração pra pedi e eu sempre fui atendida[...] era a fé que eu tinha, daí eu fazia uma novena e aquilo era fácil, era fácil, eu ficava atendida e a criança não sofria" (HÉSTIA, Segunda geração) 
HEBE e HÉSTIA relatam que os pedidos sempre foram atendidos, e por conseqüência, seus objetivos alcançados, o que levava a um desmame rápido e ausente de complicações. Após concluído o processo agradeciam as graças alcançadas, também por meio de orações e missas:

\begin{abstract}
“...mandava rezar uma missa depois que eles tavam acostumados a dormir sem mamar, pra agradecer" (HEBE, segunda geração)

"...depois que desmamava eu mandava rezar uma missa de agradecimento que deu tudo certo, eu fazia isso pra todas, no final mandava rezar uma missa" (HÉSTIA, segunda geração)
\end{abstract}

Percebemos que recorrer a orações é uma prática mencionada por mulheres-mães que representam a segunda geração da referida família. Talvez esse fato venha a ocorrer por razão da fé ter sido cultivada com maior veemência por seus pais desde que eram crianças, se compararmos com nossa atualidade. Verificamos, neste sentido, que elas trazem consigo, de maneira bastante forte, crenças religiosas que foram repassadas pela geração anterior.

Emergem das entrevistas, práticas de desmame tais como colocar algo ruim sobre a mama para a criança recusar-se de mamar, pintar com mercúrio cromo simulando um ferimento ou simplesmente dizer para o filho que não havia mais leite no peito. ATENA e HÉSTIA são as irmãs que nos contam sobre essas práticas:

\begin{abstract}
“...eu dizia que não tinha mais, que tinha dodói e ela já era grande, já tinha quatro anos e ela entendia" (ATENA, segunda geração)

"Pra desmama a minha mãe falava, dizia que era... então às vezes eu pegava e eu botei até mercúrio uma vez, dizia que era sangue, que tava doendo, que não era pra mama, mas me doía na alma, ou botava alguma coisa ruim em cima, e daí ela limpava bem com a mão e mamava igual, até botava um pouquinho de pimenta na água e passava, mas quando eu quis mesmo de sério deu certo, essas coisas não precisou fazer tantas vezes, eu tinha um santo forte que me deu proteção e deu tudo certo" (HÉSTIA, segunda geração)
\end{abstract}

As práticas que compreendiam o ato de colocar algo artificial sobre a mama eram ensinadas e motivadas por vizinhas e familiares, porém algumas mulheres-mãe recusavam-se em praticá-las, pois acreditavam que elas trariam prejuízos a si próprias e às crianças. HEBE, ATENA, HÉSTIA e DAFNE contam a respeito do repasse de informações sobre tais práticas de desmame:

"Ah, eu me lembro que tinha gente que dizia que botava pimenta, outra botou barro, mas eu nunca botei, e botavam sal, mas eu não acredito, pelo amor de Deus, vinagre tinha gente que botava e eles vinham pra chupar e era ruim, eu cuidava, eu nunca botei nada, isso pode até fazer mal pra gente e pro nenê" (HEBE, segunda geração)

“... tinha umas tias e comadres que diziam que era pra mim colocar pimenta em cima ou colocar graxa preta e até cocô de galinha diziam, mas eu que não ia botar, eu não ia ma prejudicar, ou diziam pra botar sal, mas eu sempre tentei do meu jeito, do jeito que eu achava certo." (ATENA, segunda geração)

"Sobre o desmame tinha sempre os comentários das comadres do que era pra fazer, mas eu fazia do meu jeito porque eu achava melhor" (HÉSTIA, segunda geração) "Ah, umas amigas davam mama até que a criança era muito grande e daí a criança não queria deixar de mama, daí elas passavam até pimenta na teta pra criança ter nojo e não querer mamar, e depois me ensinavam a fazer isso, mas eu nunca... imagina, nunca precisei fazer isso..." (DAFNE, terceira geração)

Os depoimentos demonstram que, da mesma forma que os fatores culturais, as vivências e as percepções individuais das mulheres-mães também exercem influências diretas na maneira com que elas irão proceder aos cuidados relativos ao desmame de seus filhos.

Podemos dizer que as mulheres-mães entrevistadas estão familiarizadas com a amamentação baseando-nos nas afirmações que seguem:

"Quanto mais familiarizada com a
amamentação for a mulher, menos
suscetível será às modas, aos modismos e
às críticas, o que faz com que o bebê não
seja desmamado segundo os hábitos de
outras mulheres. A própria essência do
relacionamento de amamentação, por outro
lado, é não estabelecer regras,
simplesmente deixar correr, quanto mais a
mãe entrar em sintonia com tal
receptividade, menos chances ela terá de
proceder arbitrariamente com respeito a
amamentação" (PRYOR, 1981, p.233).

Ouvir das mulheres-mães as estratégias que realizam para facilitar o desmame do aleitamento materno é válido para conhecermos os costumes, as crenças e as práticas que permeiam esse processo, pois assim é possível estar ao lado e apoiar as mulheres sem desqualificar suas vivências e seus valores culturais.

LEININGER (1991), teorista americana, autora da teoria da "Universalidade e Diversidade Cultural do Cuidado", aponta que para o cuidado de enfermagem ser eficaz é preciso levar em consideração as bases culturais de determinada pessoa ou grupo. Nesse sentido, ao orientarmos uma mulher-mãe sobre o desmame de seus filhos deveríamos buscar conhecer 
sua visão de mundo no que diz respeito a esse processo e, assim, pautar a assistência no respeito aos elementos constituintes de sua cultura e de sua própria vivência.

\section{CONSIDERAÇÕES FINAIS}

Através das histórias contadas percebemos que o modo como conduzem a amamentação e o desmame de seus filhos está em estreito relacionamento com os aprendizados transmitidos pelos familiares, ou seja, tem determinação dos fatores culturais como as crenças, os comportamentos, os costumes e os valores específicos do grupo. O repasse de informações é mais visível entre as mulheres-mães da segunda geração seguidas pela da terceira geração.

Além do repasse de conhecimentos de maneira intergeracional observamos que as condições sócioeconômicas, bem como a época em que vivem as pessoas, também interferem na forma de conduzirem o cuidado aos filhos. As mulheres da quarta geração referem seguir também as orientações de profissionais da saúde sendo que para as gerações anteriores esse acesso tornava-se difícil e elas então, solucionavam as dúvidas com a mãe e/ou vizinhas e amigas.

Outro fator que aparece como determinante para a adoção de práticas relacionadas ao aleitamento materno é a experiência particular de cada mulher em relação a essa questão, ou seja, a sua subjetividade, a forma como percebe a amamentação e o desmame de seus filhos.

As práticas provêm de ensinamentos dos familiares, opiniões das amigas e de experiências anteriores da mulher em relação ao processo de desmame, podendo acontecer de maneira tranqüila especialmente quando é uma decisão materna e o filho aceita sem dificuldades outro tipo de alimento. Porém, em outras situações a interrupção do aleitamento materno dá-se de forma complicada.

Estudar as práticas de desmame do leite materno nos parece importante para valorizar esse processo em suas múltiplas dimensões (pessoal, social e cultural).

\section{REFERÊNCIAS BIBLIOGRÁFICAS}

ALENCAR, Eunice M. L.. A criança na família e na sociedade. Petrópolis: Vozes, p. 38-51, 1982.

BRASIL. Conselho Nacional de Saúde. Resolução 196 de 10 de outubro de 1996. Diretrizes e normas de São Paulo. São Paulo. regulamentadoras de pesquisa envolvendo seres humanos. Brasília, 1997.

BOGDAN, Robert; BIKLEN, Sara. Investigação qualitativa em educação: uma introdução à teoria e aos métodos. Tradução de Maria João Alvarez, Sara Bahia dos Santos e Telmo Baptista. Portugal: Porto Editora, 1994.

CABRAL, Ivone Evangelista; TYRREL, Maria Antonieta Rubio. O estilo de cuidar da mãe e o trabalho da enfermagem. Revista de Enfermagem da UERJ. Rio de Janeiro, v. 3, n. 2, p. 189 - 195, out.1995.

MALDONADO, Maria Tereza. Psicologia da gravidez parto e puerpério. 4. ed. Petrópolis: Vozes, 1981.

MARCON, Sonia Silvia. Vivências de mulheres sobre o desmame (tardio) da criança. Revista Gaúcha de Enfermagem. Porto Alegre, v. 17, n. 1, p. $43-50$, jan.1996.

MARCON, Sonia Silvia; ELSEN, Ingrid. Criar os filhos: experiências de famílias de três gerações. Revista Brasileira de Enfermagem. v. 53, n. especial, p. 139-142, dez.2000.

LEININGER, M. M. Culture care diversity \& universality: a theory of nursing. New York: National League for Nursing Press, 1991.

MELATTI, Delvair Montagner; MELATTI, Julio Cesar. A criança marubo: educação e cuidados. In: ALENCAR, Eunice M. L.. A criança na família e na sociedade. Petrópolis: Vozes, p. 38-51, 1982.

MINAYO, Maria Cecília de Souza. O desafio do conhecimento: pesquisa qualitativa em saúde. 2. ed. São Paulo/Rio de Janerio: Ucitec/ Abrasco, 1993.

MINAYO, Maria Cecília de Souza (org). Pesquisa social: teoria, método e criatividade. Rio de janeiro: Vozes, 1996.

OLIVEIRA, Vera Barros de. Aspectos Psicológicos envolvidos na alimentação. Pediatria Moderna. Porto Alegre, v. 33, n. 11, p. 896 -899, nov.1997.

PRYOR, Karen. $A$ arte de amamentar. Tradução de Maria Silva Mourão Netto. São Paulo: Summus, 1981.

RAPAPPORT, Clara Regina; FIORI, Wagner da Rocha; HERZBERG, Eliana. Psicologia do desenvolvimento: a infância inicial: o bebê e sua mãe. São Paulo: EPU, 1981. v. 2.

VAN DER SAND, Isabel Cristina Pacheco. O bem estar da criança sempre em primeiro lugar: o processo de alimentação do lactente sob a ótica de mulheres-mães de ljuí/RS. 1999. Dissertação (Mestrado em Enfermagem Obstétrica) Escola de Enfermagem,
Universidade 